\title{
The impact of the COVID-19 pandemic on the environmental health of the Katunsky Biosphere Reserve
}

\author{
Aleksey Rednikin* \\ National Research Tomsk State University, 634050 Tomsk, Russia
}

\begin{abstract}
This article shows the impact of the COVID-19 pandemic on the environment of the Katunsky reserve on the eco-trail "To the Land of Lakes and Waterfalls". The research was carried out by three methods: assessment of trail degradation, camps and phytomass in damaged and reference areas. During the pandemic, a process of severe ecosystem degradation was identified, associated with a dramatic increase in the number of visitors to the reserve. Closed state borders and lifted restrictions on entry and exit to the Altai Republic have made the Katunsky Nature Reserve popular for recreational activities.
\end{abstract}

The COVID-19 pandemic has made huge changes to our everyday lives. Many regions of our planet have declared mandatory self-isolation and quarantine to prevent the spread of infection. As a result, some fields of economy have been stopped. To this day, most of state borders are closed. There is an opinion that the environmental health improves due to the global lockdown, reduction of economic activity, lack of movements and suspension of work [1]. We will consider this question on the example of Katunsky Biosphere Reserve.

The Katunsky Biosphere Reserve is located in the Altai Republic in Ust'-Koksa district far from large settlements and industrial areas. Therefore, the main negative factor threatening the Reserve's ecosystem is recreational activities.

Recreational pressure concentrates mostly on Multinskiy area, where eco-trail "To the Land of Lakes and Waterfalls" is located. This route is quite popular among tourists, as it is quite easy, its length is $9 \mathrm{~km}$, and the area has a high recreational potential and high aesthetic value [2].

To determine the level of negative anthropogenic pressure, it is necessary to evaluate the condition of eco-trail, camps and collect data on phytomass in the damaged and references areas, using the methods presented below.

The evaluation of digression of eco-trail is carried out by visual inspection and attribution to section the grade in accordance with table 1.

Table 1. Stages of eco-trail degradation [3]

\begin{tabular}{|c|c|}
\hline Grade & The condition of eco-trail \\
\hline 0 & Screes, wooden stairs and bridges \\
\hline
\end{tabular}

${ }^{*}$ Corresponding author: alexrednikin@yandex.ru 


\begin{tabular}{|c|c|}
\hline 1 & Light trampled, phytocoenosis composition is unchanged (trail depth $<20 \mathrm{~cm}$ ) \\
\hline 2 & $\begin{array}{c}\text { Tree roots go out on the surface, the trail is well-defined }(\text { depth }>20 \mathrm{~cm} \text { ), the lawn } \\
\text { grows, quick recovery }\end{array}$ \\
\hline 3 & There are additional trails and widenings, phytocoenosis has weed species \\
\hline 4 & $\begin{array}{c}\text { Weed species and anthropochores grow along the trail, there is somewhere soil erosion, } \\
\text { these sections are difficult to regenerate }\end{array}$ \\
\hline 5 & $\begin{array}{c}\text { Degradation of the vegetation cover, soil erosion, the trail is unrecoverable for a long } \\
\text { time (more than a year) }\end{array}$ \\
\hline
\end{tabular}

After that, we use GPS navigator to measure the length of all sections of the trail and create the maps of damaged and untouched sections. The lengths of different grades sections are summarized between them and diagrams are compiled from these data. This procedure is carried out twice a year: at the beginning and in the end of season of touristic activity, which is a period from June to September. This makes it possible to determine the degree of anthropogenic pressure on the trail and its surrounding ecosystem, as well as the dynamics of its recovery.

We used the average data on the digression of the eco-trail at the ends of seasons at the period from 2005 to 2019 and created the diagram (Fig. 1).

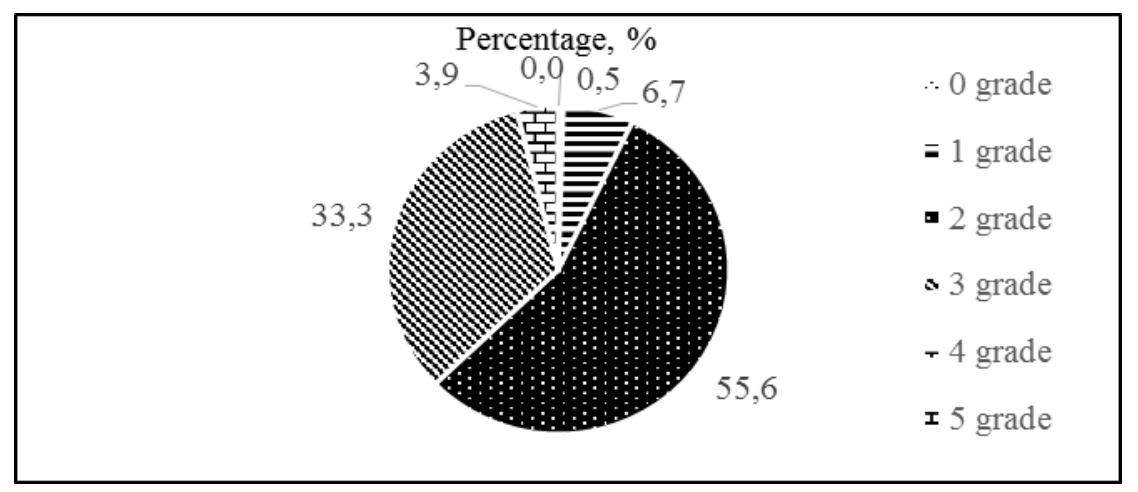

Fig. 1. Trail sections with different grades of degradation before the pandemic $[4,5]$

This diagram shows the predominance of sections with the second grade, which indicates the moderate anthropogenic pressure on eco-trail during the season. The percentage of hardregenerate sections (4-5 grades) does not exceed $4 \%$, it means, that there are not processes of degradation, and the trail will recover during the period from October to May.

However, in 2020 the situation has changed, the results of measurements taken at the end of the tourist season are showed in diagram (Fig. 2).

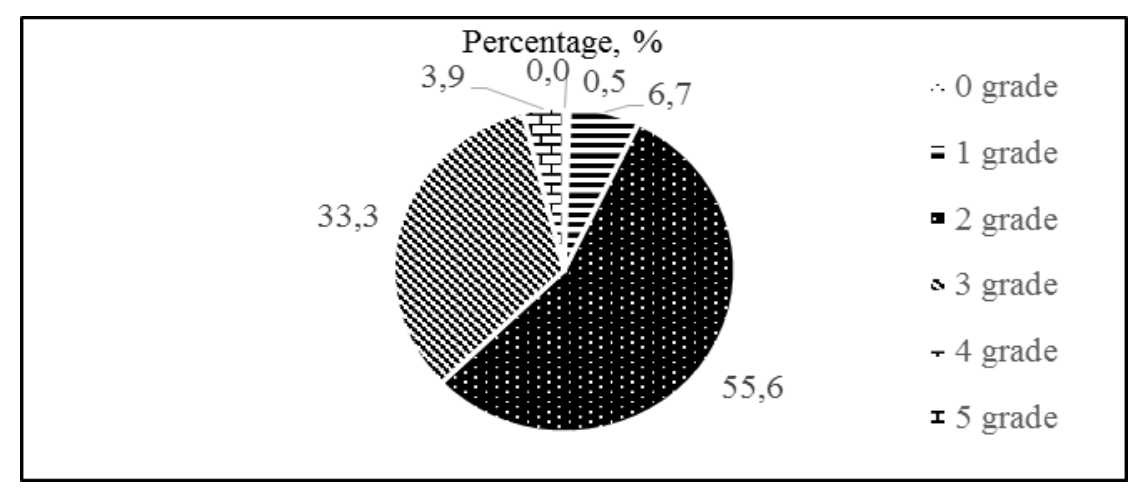

Fig. 2. Trail sections with different grades of degradation during the pandemic 
This diagram represents significant increase of the proportion of sections with 4 and 5 grades of digression. It means that the anthropogenic pressure has been critical, and the trail is in crisis condition. It can be reason of degradation of ecosystem and loss of environmental value in the future.

This type of negative anthropogenic impact has linear character, and it increases in wet periods of the year (active snowmelt, prolonged rains) [3]. This is related to wetlands, which form flooded sections, and, correspondingly, provide indirect paths and increase of space of anthropogenic pressure [5].

The places of concentration of tourists are camps. It is a required attribute of recreational use of natural recourses, which has an areal character of anthropogenic impact on the environment.

The study of condition of camps is carried out using scale of 25 to 100 points ( 25 points - the camp has good condition, there is not degradation, minimal negative impact; 100 points - the full degradation of the camp, loss of aesthetic and practical value, catastrophic impact on the ecosystem of the reserve), which has been developed by the Katunsky Reserve staff in form of a questionnaire. It covers the following aspects of recreational activity: vegetation cover, soil degradation, forest litter, indirect paths, degradation of shrubs, stand of trees, human waste, campfires, rock relocation, rubbish, insects and rodents.

This procedure is carried out at the beginning and end of tourist season. This allows to represent the condition of the camp and its negative impact on the environment in numerical terms.

There are three camps on the eco-trail "To the Land of Lakes and Waterfalls": "Near the creek", "Fishing camp" and "The Fork" on km 3, 5 and 6 of the route. These camps are equipped with toilets, wooden tables and benches, as well as fireplaces. The camp "The Fork" is additionally equipped with garbage pit, wooden shed and gazebo.

To determine the recreational pressure prior to the COVID-19 pandemic, we took averaged end-of-season data from 2014 to 2019, and end-of-season data in 2020 were used to determine the load during the pandemic. (Fig. 3).

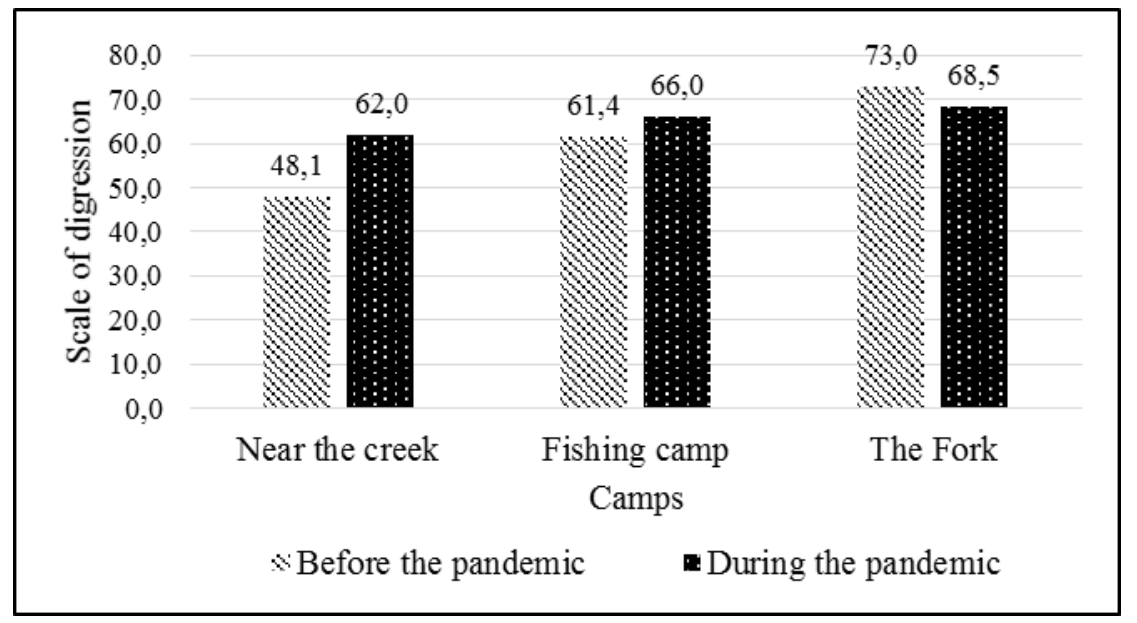

Fig. 3. The digression of the camps

This chart shows increase of degradation of the camps during the pandemic of 4,6-13,9 points on "Near the creek" and "Fishing camp". However, anthropogenic pressure to the camp "The Fork" decreased due to engineering and technical interventions that allowed the dispersal of campers and reduced their single number per unit area.

The next method of evaluation anthropogenic impact is comparison of phytomass of damaged and references areas. The reference areas are those that are unaffected by human 
influence and are located around tourist campsites. Damaged areas are areas that have been adversely affected by recreational use of natural resources.

The collection of phytomass is carried out from three reference areas and three damaged areas from each camp, each segment has area $0,25 \mathrm{~m}^{2}$ (side of square $50 \mathrm{~cm}$ ). The procedure is carried out twice a year: at the beginning and end of the season.

Phytomass has been monitored since 2013 and therefore, to determine the anthropogenic pressure before the pandemic, we took average data from 2013 to 2019 at the end of the season, and to estimate the human impact during the pandemic, data was collected at the end of the 2020 season. The results of the monitoring are shown in Fig. 4.

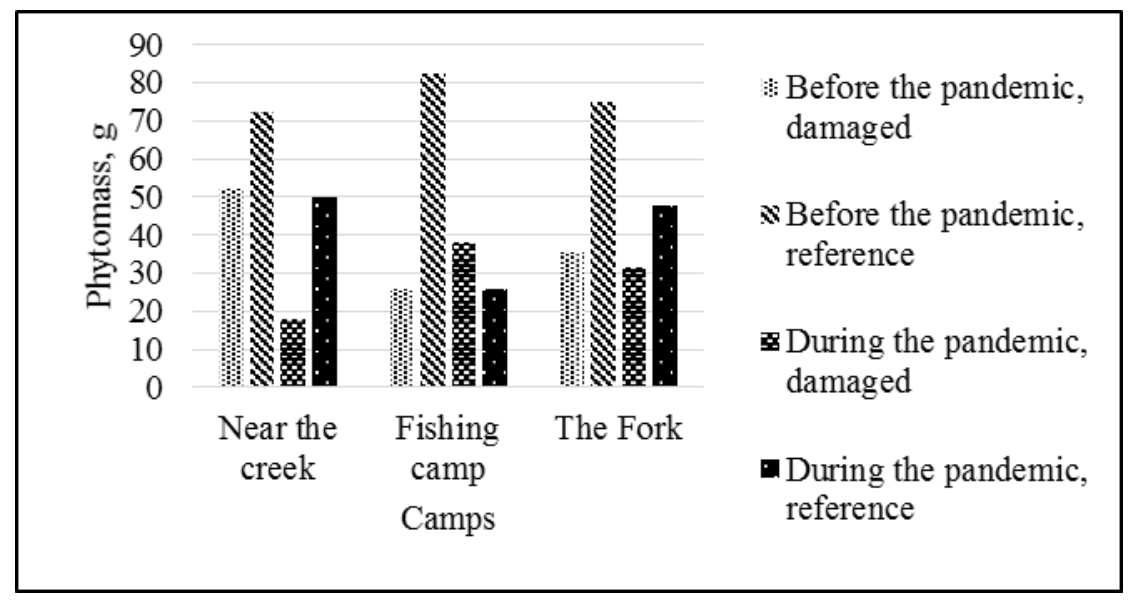

Fig. 4. Phytomass monitoring

This chart shows decrease of phytomass in damaged and reference segments during the pandemic. The exception is the "Fishing camp", in its affected areas phytomass increased in 2020 compared to the period before the COVID-19 pandemic.

All three types of monitoring of recreational pressure, which are represented at this study, shows increase of negative anthropogenic impact on the ecosystem of the Multinskiy area in the Katunsky Reserve during the pandemic compared to previous years. We made a chart of number of tourists at the period from 2013 to 2020 to determine the reason of this dynamic Fig. 5.

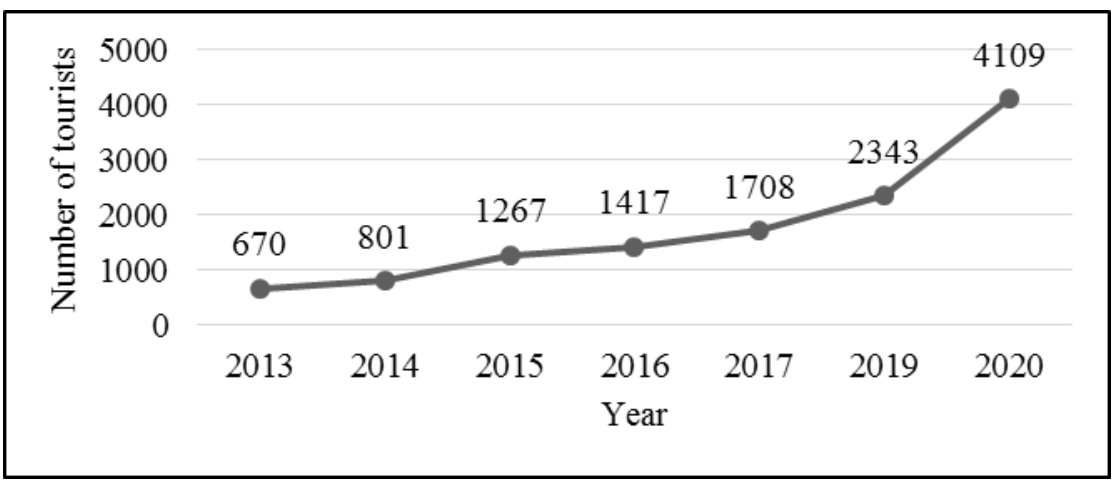

Fig. 5. Tourist numbers from 2013 to 2020 [6]

In 2020, the number of tourists who visited the eco-trail "To the Land of Lakes and Waterfalls" almost doubled compared to the previous year. The distribution of recreational visitors during the season of tourist activity by months is presented in Table 2 . 
Table 2. Number of tourists in 2020

\begin{tabular}{|c|c|}
\hline Month & Number of tourists, people \\
\hline June & 283 \\
\hline July & 1814 \\
\hline August & 1601 \\
\hline September & 411 \\
\hline
\end{tabular}

The peak of anthropogenic pressure was in June and August. This rapid increase of numbers of visitors is connected with lifted COVID-19 restrictions to enter and leave Altai Republic in the end of June. However, as a result of the closed state borders, the importance of domestic tourism has increased, contributing to an increase in tourist numbers in Katunsky Nature Reserve in 2020.

All things considered, we can conclude, that the COVID-19 pandemic and related restrictions have affected the recreational activity in the Katunsky Biosphere Reserve. The increased anthropogenic pressure has led to a process of degradation of the eco-trail "To the Land of Lakes and Waterfalls" [6], camps, as well as a decrease in phytomass. This negative impact caused by human activity in the short period leads to soil compaction, deterioration of drainage and death of soil organisms. This occurrence creates a risk of soil washout and erosion. Over-trampling of tree roots by hikers causes trees to dry out and die, which in turn can increase the likelihood of forest fires. The result of unsustainable recreational activity is the introduction of invasive and anthropochore species, as well as an increase in general littering of the territory [2].

In order to solve this problem, it is necessary to limit the passage of tourists on the route to the level of the 2013-2019s, as well as to build additional bridges in the overwatered areas, which will prevent trampling of vegetation cover and destruction of the soil [7].

\section{References}

1. N.S. Diffenbaugh [et al], Nature. 1, 470-481 (2020).

2. A. Rednikin, Environmental management and natural conservation, 60-65 (2020) (in Russian)

3. T. Yashina, L. Sharavina, Proceedings of the Tigirekskiy reserve, 1, 126-129 (2005) (in Russian).

4. L. Sharavina, Geoecology of Altai-Sayan mountainous region, 3, 159-165. (2006) (in Russian).

5. V. Nepomnyashiy, T. Yashina, A. Sonnikova. Biodiversity and monitoring of natural complexes in SPNA of Altai-Sayan eco-region. 2, 78-92. (2009) (in Russian).

6. A. Rednikin. Azimuth of GEO-sciences. 1, 82-85. (2020) (in Russian).

7. D. Dirin. Evaluation and recreational using of landscape-aesthetical resources of Ust'Koksa district of the Altai Republic. (2007) (in Russian). 